\title{
Improved long-term bonding performance of an experimental all-in-one adhesive
}

\author{
Shinichi KAKUDA, Jiale FU, Yasuko NAKAOKI, Takatsumi IKEDA, Toru TANAKA and Hidehiko SANO
}

Department of Restorative Dentistry, Division of Oral Health Science, Graduate School of Dental Medicine, Hokkaido University, Kita 13, Nishi 7, Kita-ku, Sapporo 060-8586, Japan

Corresponding author, Shinichi KAKUDA; E-mail: sk19766791ks@yahoo.co.jp

The aim of this study was to determine the performance of an experimental all-in-one adhesive. The adhesive, named MTB-200 (Kuraray Medical), contained components to enhance both bond strength and hydrophobicity. The performance of the adhesive was compared with that of CLEARFIL TRI-S BOND (Kuraray Medical) and BeautiBond (SHOFU) using micro-tensile bond strength test and ultramicroscopic observations. The study revealed that the new adhesive had the highest tensile strength value among the three adhesives over time, although transmission electron microscopic images showed the phenomenon of filler de-bonding in the adhesive resin layer. In spite of modification in the experimental adhesive, the adhesive was suspected to degrade bond performance. However, revision of the composition of adhesives would be one of the solutions to enhance durability of interface.

Keywords: Aging, Bond degradation, Dentin adhesive, Filler de-bonding, Micro-tensile bond strength

\section{INTRODUCTION}

Direct composite restoration that relies on an adhesive system had been used in daily practice under the concept of minimal intervention dentistry ${ }^{1,2}$. However, since an in vivo study revealed degradation of resindentin bonding, aging of the interface has been focused $\mathrm{on}^{3)}$. Many researchers reported infiltration into the adhesive layer. Fluid movement through potential leakage pathways within the hybrid layer was called nanoleakage and water-treeing-6). Filler de-bonding in ultra-morphology shows hydrolysis of the fillermatrix coupling ${ }^{7}$. On the other hand, potential internal enzymes, kinds of matrix metalloproteinase, contribute to the breakdown of collagen matrices ${ }^{8)}$. Those organic or inorganic decompositions are reasons for degradation of resin-dentin bonding.

In the days when two-step adhesives were the main stream of dentin adhesives, many researchers thought that clinical adhesive failure occurred due to the multiple steps involved in adhesion ${ }^{9}$. Efforts have therefore been made to reduce the number of steps. It has traditionally been explained that there are three important actions to the superficial dentin, etching, priming and bonding, in order for hybridization between dentin and resin to occur. Either "etch-and-rinse" or "self-etch" has been a strategy of two-step types of adhesive ${ }^{10)}$. Dentin adhesive systems that include all 3 actions in a one-step protocol have also become available ${ }^{11)}$. However, one-step adhesives still have problems. One-step type is not to exceed multiplestep adhesives ${ }^{12)}$, and morphologic observation has revealed that HEMA-free adhesives give rise to phase separation $^{13,14)}$ and that HEMA-containing adhesives cause hydrolysis overtime ${ }^{7}$.

Although an adequate amount of HEMA improves the bond strength of a one-step adhesive ${ }^{15)}$, both incomplete polymerization and existence of water are suspected to be reasons for the degradation of adhering with HEMA-containing adhesive ${ }^{7)}$, and the degradation are caused by ingredients of manufacture rather than manipulation errors ${ }^{16)}$

A new adhesive includes a functional additive, sodium fluoride, is thought to prevent caries. The new adhesive contains hydrophilic dimethacrylate (a crosslinking monomer), a new photo-initiator for enhanced curing and a new hydrophobic methacrylate for reduced water absorption.

In this study, we investigated the new adhesive using the traditional method for dentin adhesion. The null hypothesis was that micro-tensile bond strength of the new adhesive was not significantly different from those of contemporary single-bottle type dentin adhesives.

\section{MATERIALS AND METHODS}

\section{Materials used}

Twelve human third molars were used in this study, and every four teeth were randomly assigned to each adhesive system. The protocol of this study was approved by the Ethics Committee of Hokkaido University (admission \#2010-2). Three kinds of adhesives used in this study were shown in Table 1 . The three adhesives included two commercial all-in-one self-etch adhesives, CLEARFIL TRI-S BOND (TriS: Kuraray Medical, Okayama, Japan), BeautiBond (BB: SHOFU, Kyoto, Japan) and an experimental adhesive, MTB-200 (MTB: Kuraray Medical, Okayama, Japan).

\section{Protocol of tooth specimen preparation}

1. Teeth

Extracted caries-free human third molars were stored in $0.5 \%$ Chloramine-T solution at 4 degrees Celsius for preventing bacterial growth for no longer than 3 months before they were used in this study. 
Table 1 Adhesives used

\begin{tabular}{|c|c|}
\hline Name & Composition \\
\hline $\begin{array}{l}\text { Batch No. } \\
\text { Manufacturer }\end{array}$ & Application protocol \\
\hline MTB-200 & $\begin{array}{l}\text { MDP, Bis-GMA, HEMA, Colloidal silica, Ethanol, Water, } \\
\text { dl-Camphorquinone, Photo initiator, Hydrophilic aliphatic dimethacrylate, } \\
\text { Hydrophobic aliphatic methacrylate, Photo polymerization accelerator, } \\
\text { Chemical polymerization accelerator, Sodium fluoride, Others }\end{array}$ \\
\hline $\begin{array}{l}\text { [Lot: } 90911] \\
\text { Kuraray Medical Inc., } \\
\text { Okayama, Japan }\end{array}$ & $\begin{array}{l}\text { 1. Apply bond to the cavity wall for } 10 \mathrm{~s} \\
\text { 2. Dry with mild air for more than } 5 \mathrm{~s} \\
\text { - Dry the entire cavity wall sufficiently until the bond does not move } \\
\text { - Use a vacuum aspirator to prevent the bond from scattering } \\
\text { 3. Light-cure for } 10 \mathrm{~s} \\
\text { - Halogen light for } 10 \mathrm{~s} \text { or LED light for } 5 \mathrm{~s}\end{array}$ \\
\hline CLEARFIL TRI-S BOND & $\begin{array}{l}\text { MDP, Bis-GMA, HEMA, Colloidal silica, Ethanol, Water, dl-Camphorquinone, } \\
\text { Initiators, Accelerators, Others }\end{array}$ \\
\hline $\begin{array}{l}\text { [Lot: } 00144 \mathrm{~A}] \\
\text { Kuraray Medical Inc., } \\
\text { Okayama, Japan }\end{array}$ & $\begin{array}{l}\text { 1. Apply bond to the cavity wall for } 20 \mathrm{~s} \\
\text { 2. Dry with mild air for more than } 5 \mathrm{~s} \\
\text { - Dry the entire cavity wall sufficiently until the bond does not move } \\
\text { - Use a vacuum aspirator to prevent the bond from scattering } \\
\text { 3. Light-cure for } 10 \mathrm{~s} \\
\text { - Halogen light for } 10 \mathrm{~s} \text { or LED light for } 5 \mathrm{~s}\end{array}$ \\
\hline BeautiBond & Bis-GMA, 4-MET, TEGDMA, 6MHPAc, Acetone, Pure water, Others \\
\hline $\begin{array}{l}\text { [Lot: } 120815] \\
\text { SHOFU INC., } \\
\text { Kyoto, Japan }\end{array}$ & $\begin{array}{l}\text { 1. Apply bond and leave for } 10 \mathrm{~s} \\
\text { 2. Air-dry } \\
\text { - blow gently without scattering for } 3 \mathrm{~s} \text { and then blow more strongly } \\
\text { 3. Light-cure } \\
\text { - Halogen light for } 10 \mathrm{~s} \text { or LED light for } 5 \mathrm{~s}\end{array}$ \\
\hline
\end{tabular}

4-MET: 4-methacryloxyethyl trimellitic acid, 6MHPAc: 6-methacryloyloxyhexyl phosphonoacetate, Bis-GMA: bis-phenol-Adiglycidyl methacrylate, HEMA: 2-hydroxyethyl methacrylate, MDP: 10-methacryloxydecyl dihydrogen phosphate, TEGDMA: triethyleneglycol dimethacrylate.

\section{Bonding procedure}

Occlusal enamel was ground with a model trimmer (Model Trimmer; Morita, Tokyo, Japan) to expose dentin surface. They were finished polishing by \#600-SiC paper for $60 \mathrm{~s}$ under running water to produce a flat dentin surface with a smear layer. Dentin surfaces were clinically dried by air flowing before adhesives were applied. After applying and irradiating for each adhesive, three or four layers of the resin composite, CLEARFIL AP-X A3 (Kuraray Medical, Okayama, Japan), were incrementally made on the surface to a height of $4 \mathrm{~mm}$. Each layer was light-cured for $20 \mathrm{~s}$. The bonded specimens were stored for $24 \mathrm{~h}$ in pure water at 37 degrees Celsius.

After storage in water for $24 \mathrm{~h}$, teeth were fixed with a cyanoacrylate adhesive (Model Repair II Blue; Dentsply-Sankin, Otahara, Japan) on a platform and cut vertically into $1 \times 1 \mathrm{~mm}$ "beamed square" sticks using a low-speed diamond saw (Isomet; Buehler, Lake Bluff, IL, USA) under water cooling, according to the non- trimming technique.

3. Stress test with a PCR thermal cycler In this study, specimens were stressed with a PCR thermal cycler ${ }^{17)}$. There were two protocols: no thermal stress (non-TC group) and stress with a thermal cycle of 20,000 times (TC20k group) by a programmed PCR thermal cycler (Mastercycler; Eppendorf, Germany).

Up to ten beams could be quarried out from each tooth. Half of the beams from a tooth were provided for the non-TC protocol, and the remaining specimens were provided for the TC20k protocol. Every two or three beams were put into a 5 microliter tube with an adequate volume of distilled water, and the tubes were set on the PCR thermal cycle machine. Thermal cycling was carried out with the programmed protocol at temperatures of 5 and 55 degrees Celsius for $30 \mathrm{~s}$ each. The computed thermal cycle program was run for approximately 8 weeks. 


\section{Micro-tensile bond strength test}

Specimens were promptly employed micro-tensile bond strength test. Specimens for the non-TC group were tested immediately after cutting, and specimens for the TC20k group were tested after completion of the thermal cycle stress.

Then each stick was serially numbered and was measured in $0.1 \mathrm{~mm}$ order with a digital caliper (Absolute Digimatic; Mitutoyo Corp., Kawasaki, Japan). A specimen was mounted in the Ciucchi's jig ${ }^{18)}$ using cyanoacrylate adhesive. Each specimen was loaded in tension until failure at a crosshead speed of $1 \mathrm{~mm} /$ min in a universal testing machine (EZ test; Shimadzu, Kyoto, Japan). Load at failure was recorded in newtons and divided by the bonding surface area in square $\mathrm{mm}$ in order to calculate the bond strength in MPa. A total of twenty-eight or twenty-nine specimens (from four teeth) were used for each group.

After the tensile test, dentin side specimens were stored in a dry condition and the failure surfaces of specimens were sputter-coated with Pt-Pd for $120 \mathrm{~s}$ at an accelerating voltage of $0.4 \mathrm{kV}$ (E-1030 Ion Sputter; HITACHI, Tokyo, Japan) and then observed using a field-emission scanning electron microscope (FE-SEM: S-4000; HITACHI, Tokyo, Japan) at an accelerating voltage of $10 \mathrm{kV}$. The mode of failure was determined with microscope at a magnification of $\times 80$ and recorded as 'cohesive failure in dentin', 'cohesive failure in resin', 'interfacial failure between adhesive and dentin', 'interfacial failure between bond and composite' or 'mixed failure'.

\section{Statistical analysis of micro-tensile bond strength}

The data obtained were expressed as MPa and statistically analyzed with one-way ANOVA and Duncan's multiple comparison test at the 5\% level of significance. SPSS Statistics ver.17.0.0 (IBM Japan, Tokyo, Japan) was used for the statistical analysis.

\section{TEM observation of cross-sectional dentin specimen after} de-bonding

After observation of fractured specimens with FE-SEM, the specimens were observed with a transmission electron microscope (TEM) to analyze the resin-dentin interface. Specimen preparation for TEM followed for the standard procedures for ultramorphologic TEM examination of biological tissues. The specimens were fixed in $2.5 \%$ glutaraldehyde in $0.1 \mathrm{M}$ sodium cacodylate buffer for 1 min with the solution being changed three times. The specimens were then dehydrated in ascending grades of ethanol, $50 \%, 75 \%, 95 \%$ and $100 \%$, for $10 \mathrm{~min}$ each, with two changes of every new solution. Then, the specimens were immersed in 1 by 1 absolute ethanol and epoxy resin (Poly/Bed 812 kit, Polyscience Inc., PA) for $8 \mathrm{~h}$ with rotation at $4 \mathrm{rpm}$ (Taab Rotator type $\mathrm{N}$, Taab Laboratories Eqt., Aldermaston, England), before removing the specimens and placing them in $100 \%$ epoxy embedding resin in new bottles for rotation for 3-4 h. The resin-infiltrated specimens were embedded in a silicone rubber mold filled with 100\% epoxy resin.
Table 2 Micro-tensile bond strength to dentin in $\mathrm{MPa}$

\begin{tabular}{|c|c|c|c|}
\hline & MTB-200 & $\begin{array}{c}\text { CLEARFIL } \\
\text { TRI-S BOND }\end{array}$ & BeautiBond \\
\hline non-TC & $\begin{array}{c}72.5(17.2)^{\mathrm{A}} \\
n=28\end{array}$ & $\begin{array}{c}64.8(14.2)^{\mathrm{A}, \mathrm{B}} \\
n=28\end{array}$ & $\begin{array}{c}31.0(17.1)^{\mathrm{C}} \\
n=28\end{array}$ \\
\hline $\begin{array}{l}20,000 \\
\text { thermal cycles }\end{array}$ & $\begin{array}{c}69.7(19.3)^{\mathrm{A}} \\
n=29\end{array}$ & $\begin{array}{c}58.7(12.9)^{\mathrm{B}} \\
n=29\end{array}$ & $\begin{array}{c}26.9(14.8)^{\mathrm{C}} \\
n=29\end{array}$ \\
\hline
\end{tabular}

Mean (SD); $n=$ total number of specimens.

No specimen failed before testing.

Values with the same superscript letter are not significantly different $(p>0.05)$.

The epoxy resin blocks in the mold were polymerized in an oven at 60 degrees Celsius for more than $48 \mathrm{~h}$.

In order to observe the fracture area, TEM specimens were sliced parallel to the long axis of teeth using a diamond knife (DiATOME, Bienne, Switzerland) and in an ultramicrotome (Ultracut, Leica, Vienna, Austria) to a thickness of about 90-100 $\mathrm{nm}$ and then examined by a transmission electron microscope (JEM-1400; JEOL, Tokyo, Japan) at an accelerating voltage of $80 \mathrm{kV}$.

\section{RESULTS}

\section{Micro-tensile bond strength}

Mean micro-tensile bond strength, standard deviation and total number of specimens per group are summarized in Table 2. In the condition of 20,000 thermal cycles, MTB showed a significantly higher value than that of TriS. BB, HEMA-free adhesive, showed a lower value than those of MTB and TriS, HEMAcontaining adhesives. In the non-TC group, there was no significant difference between the tensile bond strength of the HEMA-containing adhesives $(p>0.05)$. There was no pre-testing failure occurred in any of the specimens.

\section{FE-SEM observation and failure mode classification}

Typical images of the de-bonded surfaces with FE-SEM are shown in Fig. 1. Table 3 shows the failure modes of the specimens according to bonding agent, number of thermal cycles and fracture type. The trends of fracture mode were different between BB and the others. Almost all of the MTB and TriS specimens showed cohesive failure in adhesive resin. On the other hand, all of the $\mathrm{BB}$ specimens showed mixed failure.

\section{TEM observation of cross-sectional dentin specimens after tensile tests}

Typical images of the resin dentin-interface produced by each adhesive are shown in Fig. 2. Irrespective of thermal cycles, in MTB, TriS and BB, the fracture surface indicated by the $\mathrm{Pt}-\mathrm{Pb}$ ion spatter coating appeared above the adhesive resin layer. Nano-fillers were originally contained in both MTB and TriS. It was observed that those fillers scattered all over the 


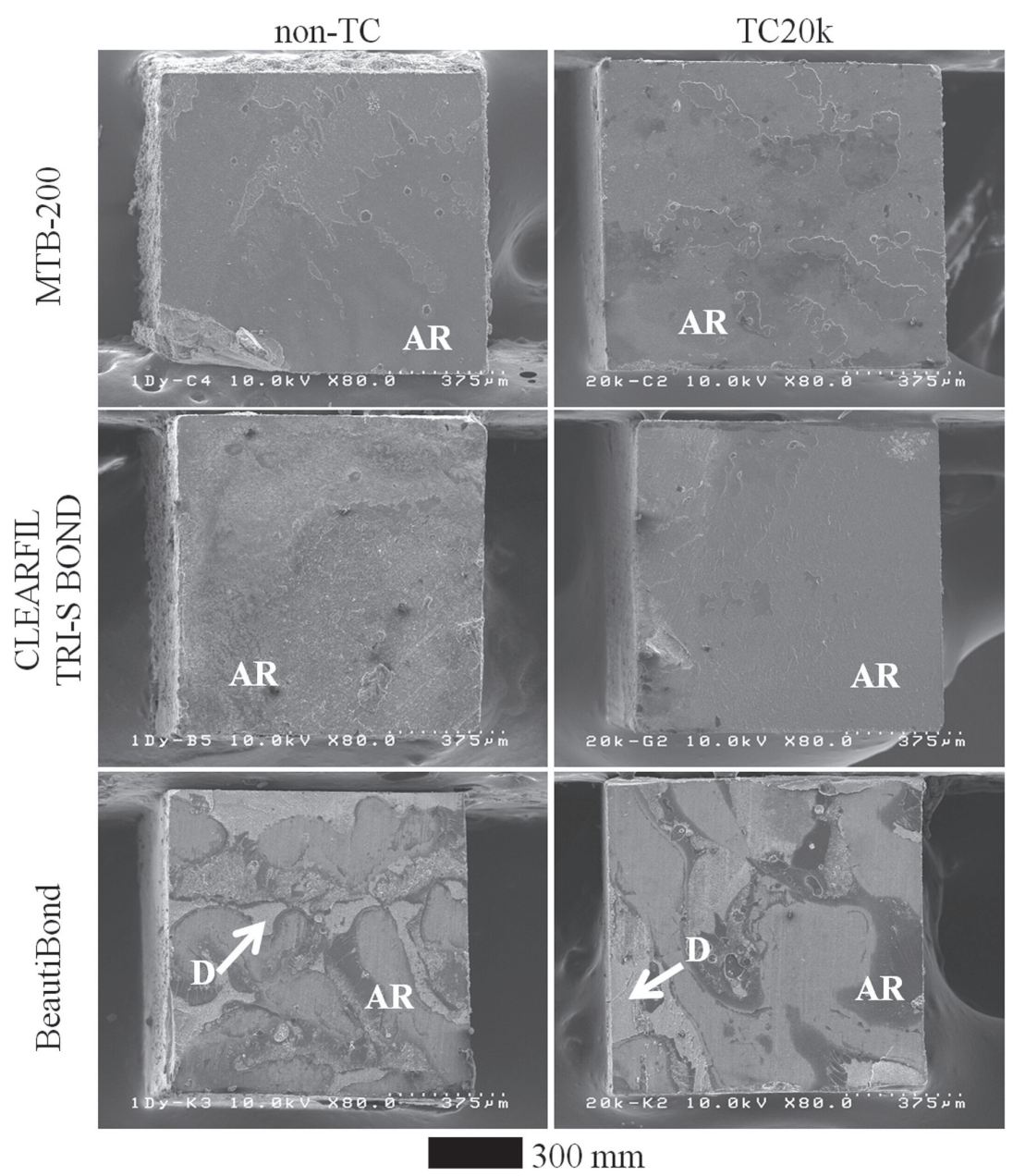

Fig. 1 Field-emission scanning electron micrographs of de-bonded samples show their fractured surfaces.

MTB-200 samples of both non-TC and TC20k show that fractures occur in an adhesive resin. CLEARFIL TRI-S BOND samples of both conditions also show cohesive failure in adhesive resin layer. De-bonded samples which BeautiBond has been applied show characteristic appearances. The appearance indicates an uneven resin effect to dentin or an uncompleted infiltration into the affected dentin.

Abbreviations: AR, adhesive resin; $\mathrm{D}$, dentin

Table 3 Failure mode

\begin{tabular}{|c|c|c|c|c|c|}
\hline & $\begin{array}{l}\text { Cohesive } \\
\text { failure in } \\
\text { dentin }\end{array}$ & $\begin{array}{l}\text { Cohesive } \\
\text { failure in } \\
\text { adhesive } \\
\text { resin }\end{array}$ & $\begin{array}{l}\text { Interfacial } \\
\text { failure } \\
\text { between } \\
\text { adhesive } \\
\text { and dentin }\end{array}$ & $\begin{array}{l}\text { Interfacial } \\
\text { failure } \\
\text { between } \\
\text { bond and } \\
\text { composite }\end{array}$ & $\begin{array}{l}\text { Mixed } \\
\text { failure }\end{array}$ \\
\hline MTB-200 non-TC & $0.0 \%$ & $91.3 \%$ & $0.0 \%$ & $0.0 \%$ & $8.7 \%$ \\
\hline MTB-200 TC20k & $0.0 \%$ & $91.7 \%$ & $0.0 \%$ & $0.0 \%$ & $8.3 \%$ \\
\hline CLEARFIL TRI-S BOND non-TC & $0.0 \%$ & $92.6 \%$ & $0.0 \%$ & $0.0 \%$ & $7.4 \%$ \\
\hline CLEARFIL TRI-S BOND TC20k & $0.0 \%$ & $81.5 \%$ & $0.0 \%$ & $0.0 \%$ & $18.5 \%$ \\
\hline BeautiBond non-TC & $0.0 \%$ & $0.0 \%$ & $0.0 \%$ & $0.0 \%$ & $100.0 \%$ \\
\hline BeautiBond TC20k & $0.0 \%$ & $0.0 \%$ & $0.0 \%$ & $0.0 \%$ & $100.0 \%$ \\
\hline
\end{tabular}



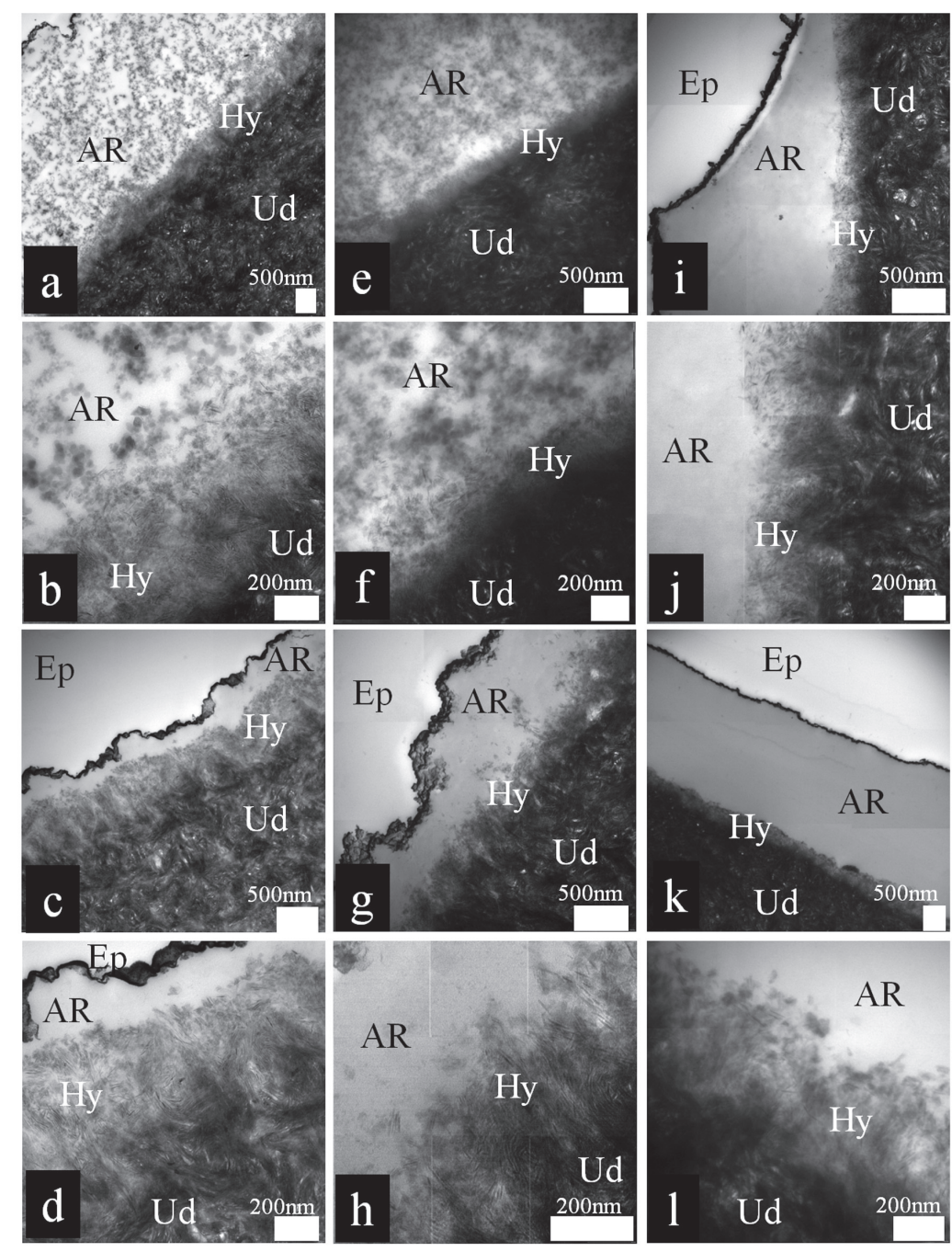

Fig. 2 Transmission electron micrographs of fractured micro-tensile bond strength samples show the dentin sides of fractured samples.

All samples are non-de-mineralized and non-stained. All of the TEM samples were sliced to approximately 90-100 $\mathrm{nm}$ in thickness.

(a) and (b) show a specimen prepared with MTB-200 and stored for one day. In (a), the adhesive layer includes widely distributing granules. The black line with sputtering ion indicates the fractured surface. A middle level transparency band exists between the unaffected dentin and adhesive layer. (b), which is a high magnification image of (a), shows nano-fillers distributing among the adhesive layer and hydroxyapatite crystals in the hybrid layer.

(c) and (d) show a specimen prepared with MTB-200 and stored with a PCR thermal cycler for 20,000 times. In (c), the image shows a plain adhesive layer without any granules. (d), which is a high magnification image of (c), shows a simple clear adhesive layer, but hydroxyapatite crystals can be seen.

(e) and (f) show a specimen prepared with CLEARFIL TRI-S BOND and stored for one day. In (e), the adhesive layer includes granules as in the image in (a). The unaffected dentin and mid-transparency band are shown. (f), which is a high magnification image of (e), shows nano-fillers distributing all around the adhesive layer and the existence of hydroxyapatite crystals in hybrid layer.

(g) and (h) show a specimen prepared with CLEARFIL TRI-S BOND and stored with a PCR thermal cycler for 20,000 times. In (g), the image shows a plain adhesive layer with no granules. (h), which is a high magnification image of (g), shows a simple adhesive layer, but hydroxyapatite crystals can be seen.

(i) and (j) show a specimen prepared with BeautiBond and stored for one day. In (i), the adhesive layer contains nothing. The black sputtering line is smoother than another bond. (j), which is a high magnification image of (i), shows a hybrid layer containing hydroxyapatite crystals beside of adhesive layer.

(k) and (l) show a specimen prepared with BeautiBond and stored with a PCR thermal cycler for 20,000 times. In (k), the image shows a plain adhesive layer. (l), which is a high magnification image of (l), shows a hybrid layer containing hydroxyapatite crystals.

Abbreviations: AR, adhesive resin; Ep, epoxy resin; Hy, hybrid layer; Ud, unaffected dentin. 
remaining adhesive resin layer (MTB and TriS, non-TC). However, the TC20k group specimens of MTB and TriS did not show any fillers. In other words, the difference between images for the non-TC group and TC20k group was the appearance of filler. On the other hand, hydroxyapatite crystals remained scattered throughout the hybrid layer.

\section{DISCUSSION}

Water storage is a common technique for examining the long-term durability of a resin-dentin interface ${ }^{7}$. In addition, thermal cycle test shortens time passing for aging ${ }^{17)}$. A programmed PCR thermal cycling process can regulate temperature and terms automatically.

A micro-tensile bond strength test can objectively express bonding performance. Since the proposal of this method for assessing adhesives ${ }^{19}$, it has been used worldwide. Human teeth specimens for tensile testing generally have some modified forms such as "hourglass shape $^{3,20) ", ~ " b e a m e d ~ s q u a r e ~}{ }^{19) "}$ and "cylinder form". In the present study, the form of specimen used was a " $1 \times 1 \mathrm{~mm}$ squared beam". The form is relatively less sacrifice tooth structure than trimming type ${ }^{21}$. The most important benefit of the "beamed square" modification is that the beams can be divided into multiple condition groups since many specimens can be obtained from a single tooth $^{21)}$ : specimens for initial bonding performance and others for long-term. The second important benefit of the "beamed square" modification is size. Small diameter of specimen accelerate aging model in a relatively short period of time ${ }^{21}$. A PCR thermal cycler provides not only a regulation of thermal cycle process but also acceleration for aging ${ }^{17)}$.

MTB specimens in the TC20k group showed a significantly higher bonding value than that of TriS specimens in the same condition. Therefore, the null hypothesis that micro-tensile bond strength of the new adhesive is not significantly different from those of contemporary single-bottle type dentin adhesives was rejected. The concept both a new hydrophobic component and an improvement of polymerization would be effective for enhancing bonding performance. On the other hand, the stress condition of 20,000 thermal cycles for approximate 2 months did not diminish bond strength in the same adhesive, although many researchers reported that the bonding value of a dentin adhesive system would decrease in the long term. Therefore, the results of the micro-tensile bond strength tests did not indicate bonding degradation in the present study. However, in spite of the similar components in MTB and TriS, the results of micro-tensile bond strength test were differing between the two adhesives.

Failure modes of BB showed mixed failure which included both cohesive failures in adhesive resin and interfacial failure at the resin-dentin boundary in all specimens. On the other hands, almost of fracture formations of MTB and TriS were cohesive failure in adhesive resin and others were mixed failure. A trend of correlation between high bond strengths and rate of cohesive failure in this study agreed that cohesive failure was thought to be associated with higher bond strengths ${ }^{22,23)}$.

Fluorine plays important roles in dentistry including prevention of caries and enhancement of tooth substrates. Glass ionomer cement is one of restoration materials that contain fluoride for the two purposes ${ }^{24}$. Regarding, the new experimental adhesive evaluated in the present study, hydrophobic methacrylate monomer contains a fluorocarbon chain. That is, fluorocarboncontaining polymers have a low surface energy, which are highly hydrophobic ${ }^{25}$. Organo-fluorine-rich resins can therefore provide inert polymers that excellently display hydrophobicity and resistance to softening by a wide range of chemicals ${ }^{26)}$.

FE-SEM and TEM observations are widely used for analyzing phenomena at the interface between an adhesive resin and tooth substrate. There have been many studies using electron microscopic observations to determine the mechanisms of bonding degradation ${ }^{27-29}$ since the phenomenon of nanoleakage was described for the first time in $1995^{4,30)}$. Bonding degradation in vitro is a result of affection related to water molecules.

After the adhering step, the adhesive layer would absorb water. These residual water molecules in the adhesive layer cause activation of enzymes and/or debonding of bonded-fillers. Those small collapses might cause a decrease in mechanical tensile bond strength. TEM images of filler de-bonding strongly suggest that polymer hydrolysis occurred due to water ${ }^{7)}$.

Unfortunately, TEM images also support the possibility of hydrolytic reaction because the phenomenon of filler de-bonding was clearly shown. A difference in the thermal stress conditions might strongly correlate to the appearance of filler remaining or de-bonding in TEM images. That is, aging with the thermal cycle might lead to hydrolysis between fillers and adhesive $\operatorname{resin}^{7}$. Concerning each adhesive, MTB showed a trend to be degraded in the long term, although the adhesive was improved comparing to TriS in the situation of TC20k. Clinically, discoloration appeared more rapidly than retention loss as an adhesive failure ${ }^{31}$. MTB cannot escape from those water affections, despite the addition of hydrophobic molecules. Therefore, it is an unpredicted that hydrophobic molecule additives are effective for improving adhesive degradation. However, MTB would be more durable than TriS, because it shows better bonding strength after the thermal cycle test. Result showed that filler de-bonding appeared without reduction of bond strength. This suggested a difference of chemical resolution between resin-filler bond and polymer of resin matrix. Matrix resin polymer mainly would have resisted tensile strength force in this study.

Although HEMA improves the bond strength of a one-step self-etch adhesive ${ }^{15}$, the concept of HEMA-free is expected to escape from the influence of HEMA related to water. However, phase separation is often pointed out as a disadvantage of the HEMA-free type. On the other hand, HEMA brings solvents back into solution ${ }^{13)}$. Droplets in adhesive layer are 
morphologically observed in the HEMA-free and often exist on the dentin side of the adhesive layer ${ }^{13,14)}$. The absence of a resin substance might cause a decrease in mechanical tensile bond strength. Figure 1 shows a fracture surface of a de-bonded specimen to which BeautiBond was applied and was stored in distilled water for $24 \mathrm{~h}$. An FE-SEM image of the fracture surface of the specimen bonded with BeautiBond exhibited a characteristic appearance of residual resin. The picture aroused the result of phase separation due to both biasing distribution of ingredients in adhesive droplets and non-uniform interactions with the dentin surface.

Direct resin composite restoration is one of the most widespread practical treatments. The prognosis strongly depends on the dentin adhesive system $^{32}$. Therefore, the durability of bonds between adhesive resins and dentin is important for the stability of bonded restoration ${ }^{15)}$. Despite great progress in adhesive systems, the resin-dentin interface is concerned to be the sensitive portion of conservative dentistry. But the challenge with function to cover already weak point that is hydrophilic rather than bond strength in present study would be one of direction to improve the credibility of interface between dentin and adhesive resin in future.

\section{CONCLUSIONS}

1. A new experimental all-in-one adhesive exhibited better bond strength than other commercially available adhesives used in this study.

2. Filler de-bonding occurred in the new adhesive overtime.

\section{ACKNOWLEDGMENTS}

We thank the respective manufacturers for providing the dental materials.

\section{REFERENCES}

1) Yoshiyama M, Doi J, Nishitani Y, Itota T, Tay FR, Carvalho RM, Pashley DH. Bonding ability of adhesive resins to cariesaffected and caries-infected dentin. J Appl Oral Sci 2004; 12: 171-176.

2) Toledano M, Cabello I, Yamauti M, Osorio R. Differential resin-dentin bonds created after caries removal with polymer burs. Microsc Microanal 2012; 18: 497-508.

3) Hashimoto M, Ohno H, Kaga M, Endo K, Sano H, Oguchi H. In vivo degradation of resin-dentin bonds in humans over 1 to 3 years. J Dent Res 2000; 79: 1385-1391.

4) Sano H, Takatsu T, Ciucchi B, Horner JA, Matthews WG, Pashley DH. Nanoleakage: leakage within the hybrid layer. Oper Dent 1995; 20: 18-25.

5) Tay FR, Pashley DH, Yiu C, Cheong C, Hashimoto M, Itou K, Yoshiyama M, King NM. Nanoleakage types and potential implications: evidence from unfilled and filled adhesives with the same resin composition. Am J Dent 2004; 17: 182-190.

6) Hashimoto M, Tay FR, Ito S, Sano H, Kaga M, Pashley DH. Permeability of adhesive resin films. J Biomed Mater Res B Appl Biomater 2005; 74: 699-705.

7) Van Landuyt KL, De Munck J, Mine A, Cardoso MV, Peumans M, Van Meerbeek B. Filler debonding \& subhybrid- layer failures in self-etch adhesives. J Dent Res 2010; 89: 1045-1050.

8) Pashley DH, Tay FR, Yiu C, Hashimoto M, Breschi L, Carvalho RM, Ito S. Collagen degradation by host-derived enzymes during aging. J Dent Res 2004; 83: 216-221.

9) Hanabusa M, Mine A, Kuboki T, Momoi Y, Van Ende A, Van Meerbeek B, De Munck J. Bonding effectiveness of a new 'multi-mode' adhesive to enamel and dentine. J Dent 2012; 40: 475-484.

10) Van Meerbeek B, Yoshihara K, Yoshida Y, Mine A, De Munck J, Van Landuyt KL. State of the art of self-etch adhesives. Dent Mater 2011; 27: 17-28.

11) Nikaido T, Ichikawa C, Li N, Takagaki T, Sadr A, Yoshida Y, Suzuki K, Tagami J. Effect of functional monomers in allin-one adhesive systems on formation of enamel/dentin acidbase resistant zone. Dent Mater J 2011; 30: 576-582.

12) Nakaoki Y, Sasakawa W, Horiuchi S, Nagano F, Ikeda T, Tanaka T, Inoue S, Uno S, Sano H, Sidhu SK. Effect of double-application of all-in-one adhesives on dentin bonding. J Dent 2005; 33: 765-772.

13) Van Landuyt KL, De Munck J, Snauwaert J, Coutinho E, Poitevin A, Yoshida Y, Inoue S, Peumans M, Suzuki K, Lambrechts P, Van Meerbeek B. Monomer-solvent phase separation in one-step self-etch adhesives. J Dent Res 2005; 84: 183-188.

14) Fukuoka A, Koshiro K, Inoue S, Yoshida $Y$, Tanaka T, Ikeda T, Suzuki K, Sano H, Meerbeek BV. Hydrolytic stability of one-step self-etching adhesives bonded to dentin. J Adhes Dent 2011; 13: 243-248.

15) Van Landuyt KL, Snauwaert J, Peumans M, De Munck J, Lambrechts P, Van Meerbeek B. The role of HEMA in onestep self-etch adhesives. Dent Mater 2008; 24: 1412-1419.

16) Van Meerbeek B, De Munck J, Yoshida Y, Inoue S, Vargas M, Vijay P, Van Landuyt K, Lambrechts P, Vanherle G. Buonocore memorial lecture. Adhesion to enamel and dentin: current status and future challenges. Oper Dent 2003; 28: 215-235.

17) Nakata T, Fujita M, Nagano F, Noda M, Sano H. Effect of a new thermal cycling method on bond strength of two-step self-etching adhesive systems. Dent Mater J 2007; 26: 635641.

18) Paul SJ, Welter DA, Ghazi M, Pashley D. Nanoleakage at the dentin adhesive interface vs microtensile bond strength. Oper Dent 1999; 24: 181-188.

19) Shono Y, Ogawa T, Terashita M, Carvalho RM, Pashley EL, Pashley DH. Regional measurement of resin-dentin bonding as an array. J Dent Res 1999; 78: 699-705.

20) Sano H, Shono T, Sonoda H, Takatsu T, Ciucchi B, Carvalho R, Pashley DH. Relationship between surface area for adhesion and tensile bond strength evaluation of a micro-tensile bond test. Dent Mater 1994; 10: 236-240.

21) Shono Y, Terashita M, Shimada J, Kozono Y, Carvalho RM, Russell CM, Pashley DH. Durability of resin-dentin bonds. J Adhes Dent 1999; 1: 211-218.

22) Pereira PN, Okuda M, Sano H, Yoshikawa T, Burrow MF, Tagami J, Effect of intrinsic wetness and regional difference on dentin bond strength. Dent Mater 1999;15: 46-53.

23) Sidhu SK, Omata Y, Tanaka T, Koshiro K, Spreafico D, Semeraro S, Mezzanzanica D, Sano H, Bonding characteristics of newly developed all-in-one adhesives. J Biomed Mater Res B Appl Biomater 2007; 80: 297-303.

24) Okuyama K, Murata Y, Pereira PN, Miguez PA, Komatsu H, Sano H. Fluoride release and uptake by various dental materials after fluoride application. Am J Dent 2006; 19: 123-127.

25) Douglas WH, Craig RG, Chen CJ. A new composite restorative based on a hydrophobic matrix. J Dent Res 1979; 58: 19811986.

26) Stansbury JW, Antonucci JM. Dimethacrylate monomers 
with varied fluorine contents and distributions. Dent Mater 1999; 15: 166-173.

27) Aoki K, Kitasako Y, Ichinose S, Burrow MF, Ariyoshi M, Nikaido T, Tagami J. Ten-year observation of dentin bonding durability of 4-META/MMA-TBB resin cement —a SEM and TEM study. Dent Mater J 2011; 30: 438-447.

28) De Munck J, Shirai K, Yoshida Y, Inoue S, Van Landuyt K, Lambrechts P, Suzuki K, Shintani H, Van Meerbeek B. Effect of water storage on the bonding effectiveness of 6 adhesives to Class I cavity dentin. Oper Dent 2006; 31: 456-465.

29) Ferrari M, Mason PN, Goracci C, Pashley DH, Tay FR. Collagen degradation in endodontically treated teeth after clinical function. J Dent Res 2004; 83: 414-419.

30) Van Meerbeek B. The "myth" of nanoleakage. J Adhes Dent 2007; 9: 491-492.

31) Heintze SD, Thunpithayakul C, Armstrong SR, Rousson V. Correlation between microtensile bond strength data and clinical outcome of Class V restorations. Dent Mater 2011; 27: 114-125.

32) Sano H, Yoshikawa T, Pereira PN, Kanemura N, Morigami M, Tagami J, Pashley DH. Long-term durability of dentin bonds made with a self-etching primer, in vivo. J Dent Res 1999; 78: 906-911. 